\author{
Lavdosh Malaj \\ University of Vlora \\ e-mail: lavdoshmalaj@gmail.com \\ ORCID: 0000-0002-2451-460X
}

\title{
SUMMARY STRATEGIES FOR LITERARY TEXTS IN ENGLISH
}

\begin{abstract}
One of the problems when students go to university is that they are faced with insufficient skills (reading, summarizing and writing). These skills are not just an option for students - they are a necessity. One of these skills is text summarizing. Summarizing strategies may be called the gist of the literary text. Different summarization strategies may be required for different text types and lengths. The ability to summarize well means your reading comprehension and writing skill should be excellent. Summarization is a high-level comprehension strategy which is effective in improving reading achievement and text summary quality.

Several approaches have been developed to analyse summarizing skills which are required to teach and learn English at all levels especially at university level. The research was conducted among students of the second year English department at University of Vlora. The summaries reflect the major differences among the strategies used by skilled and unskilled students. The skilled students produce coherent linguistic and syntactic structures. Skilled (high-proficiency) students use semantic and prepositional phrases more than unskilled students (low-proficiency). Thus, the skilled students do not distort ideas of the original text but distort subject-verb order. When they summarize, we can easily distinguish the way in which they combine idea units across two or more paragraphs. The summaries reflect that students write very long sentences. The margin of errors is considerable due to the mother tongue influence and their level of English.
\end{abstract}

Keywords: summary, text, skill, strategy, student.

\section{Introduction}

Linguists have shown special interest regarding the differences between skilled and unskilled students in learning English. Numerous studies have been conducted providing information on teacher training who will draft teaching programs and strategies to overcome students' learning problems (Cohen 1998, Hsiao \& Oxford 2002; MacIntyre \& Noels, 1996). 
In this framework, it is widely accepted that the ability to read and to understand the text is a necessity for both success in school and lifelong learning. Reading ability is just a skill that you teach students, and it is developed ad infinitum. The issue of successful learning at different levels is related to the ability to read and write. Taking as an example the New Literacy Studies (NLS) discourse, Gee (1990, 1991, 2000, 2001) and Street (1984, $1988,1995,2000,2001,2003)$ show that education varies over time and is dependent on the space and meaning that different people attribute to it.

When reading a student needs to combine his/her knowledge with the presentation in the text, understand the different elements, find the main idea and supporting details as well as distinguish between the main idea and the supporting ones. According to Clark $(1982)^{1}$ this is a process of cognitive activity of thinking and learning which are assigned by reconstructing, interpreting and summarizing reading material.

Research on summarizing strategies by speakers of English as a second language have attracted the interest of some linguists because it has been observed that students' ability to summarize a literary text is essential to learning development at different school levels. Summarizing is one of the most important academic skills at the university level. Students are required to summarize complex concepts and information in each subject.

Moreover, teachers often use this complex task to assess students' understanding of concepts and materials. In foreign language studies, the process of conducting the summary becomes a valuable assessment tool to track students' progress in learning a foreign language.

In today's world where information technology is becoming more sophisticated day by day, students are exposed to an infinite amount of information. They must obtain the information, select the most appropriate one for their academic needs, analyse and reproduce it. Under these conditions their ability to summarize this information is the key to academic success. This ability is necessary even later in life, when they have to operate with diverse information about their profession.

According to McAnulty, 1981, the summary is a short version with your own words of someone else's writing, an abbreviation that reproduces the thought, emphasis, and tone of the original. It summarizes all the important facts of the original- general thesis, main points, important supporting details -, but unlike a paraphrase it omits and/or reduces descriptive details.

An important concern to teachers at all levels of education around Albania is the enormous difference that exists among students in text reading comprehension and summarizing not only in second language learning but also in their mother tongue and other subjects. 
The ability to write an effective summary can be the most important ability that a student can have in order to understand and interpret the text, as well as to write on that specific topic. We should be able to use summarization skills and to understand the meaning of the text.

When we want to analyse this text we should consider how these sentences are related to one another and the ideas they express. But when the text is too long, what do we do? In this case, we use a brief summary of the text so that the reader can determine quickly the purpose of the text. We should mention summary strategies that students should bear in mind when summarizing any kind of literary or scientific text.

The aim of this paper is to show the effects of summarization strategies on literary text summary in second language learning. The objective of summary strategies is to reproduce the main ideas of the text. The purpose of a summary is to give the reader a brief clear and objective picture of the original text. Most importantly, the summary restates only the main points of a text without giving examples or details.

\section{Rules for Summarizing a literary text}

The students should follow a set of rules which guides them in developing a high organized summary. Marzano, Robert J., and Debra J. Pickering, and Jane E. Pollock, (2001) suggest the following rules for summarizing a literary text:

Erase things that don't matter. Only write down important points. If it is not something that will help you understand or remember, then don't write it down. Think of it this way ... If you had to pay money for every word you write down, which words would you choose to include in your notes?

Erase things that repeat. Delete redundant material. In note taking, time and space are precious. If a word or phrase says basically the same thing you have already written down, and then don't write it again!

Trade, general terms for specific names. Focus on the big picture. Long, technical lists are hard to remember. If one word will give you the meaning, then less is more.

Select a topic sentence, or invent one if it is missing. Topic sentences state the main idea. Select or write down a topic sentence to focus your study on the main idea.

Teaching students how to summarize any given text improves their reading comprehension and learning strategies (Baumann, 1984, Taylor, 1982). 
"Summarizing and reviewing integrate and reinforce the learning of major points... these structuring elements not only facilitate memory for the information but allow for its apprehension as an integrative whole with recognition of the relationships between parts." (J. E. Brophy and T. L. Good, 1986)

\section{Marking of errors}

Three categories of errors were marked and are described below (examples were taken from participants' writing in the study):

Morphological errors: all errors in verb tense or form; plural or possessive ending incorrect, omitted, or unnecessary; subject-verb agreement errors; article or other determiner incorrect, omitted, or unnecessary.

Semantic errors: errors in word choice, including preposition and pronoun errors; omitted words or phrases, unnecessary words or phrases.

Spelling errors included only if the (apparent) misspelling resulted in an actual English word.

Syntactic errors: errors in sentence/clause boundaries (run-ons, fragments, comma splices), word order, other ungrammatical sentence constructions.

On the one hand, it gives the audience the opportunity to see different viewpoints, and it is up to the audience what they want to believe. On the other hand, Ferris and Roberts (2001) used five categories (verb errors, noun ending errors, article errors, wrong word, and sentence structure). And Chandler (2003) used 23 types of errors.

I used only three categories to avoid overlapping and to achieve higher interrater-reliability on categorization. It was important to have the same teacher-researcher marking all errors in the same way. Another assessor, a college ESL teacher and native speaker of English, marked $10 \%$ of the papers in order to calculate inter-rater agreement. This was calculated by dividing the number of errors marked by only one assessor by the total number of errors (an average of each assessor's count), as Chandler (2003) did. The percentage agreement on the overall number of errors was $96 \%$. The percentage agreement was $90 \%$ on the number of morphological errors, $75 \%$ on that of semantic errors, $44 \%$ on that of syntactic errors. Due to the low percentage agreement, the syntactic errors were not analysed as useful data. 


\section{The results of text summaries}

The summary of a literary text is one of the most effective strategies in teaching and learning. Evaluating the effectiveness of the summarization is a key strategy in the development of students; a particular study was conducted with the students of the University of Vlora. Summary strategies, developed by students at the University of Vlora, show how these students use the ideas, syntactic, semantic and linguistic connections, as well as the mistakes they make in sentences and at a paragraph level. One of the factors that distinguishes high proficiency from average and low proficiency students is the development of the ideas in the original text. Low proficiency and most of average proficiency students simply copy the original text structures, while high proficiency students work through these ideas. The original text was Revised enhanced lecture in opposition to the Kyoto Protocol on reducing greenhouse gas emissions ${ }^{2}$.

According to this study we had the following results of the text summaries:

Table 1

Used ideas (high proficiency students)

\begin{tabular}{|c|c|c|c|c|}
\hline \multicolumn{5}{|c|}{ High proficiency students } \\
\hline Text's ideas & In one sentence & In one paragraph & $\begin{array}{c}\text { Across } \\
\text { two paragraphs }\end{array}$ & Total \\
\hline 1 & 3 & 2 & 1 & 6 \\
\hline 2 & 2 & 1 & - & 3 \\
\hline 3 & 1 & 1 & - & 2 \\
\hline 4 & 2 & - & 1 & 3 \\
\hline
\end{tabular}

Table 2

Used ideas (average proficiency students)

\begin{tabular}{|c|c|c|c|c|}
\hline \multicolumn{5}{|c|}{ Average proficiency students } \\
\hline Text's ideas & In one sentence & In one paragraph & $\begin{array}{c}\text { Across } \\
\text { two paragraphs }\end{array}$ & Total \\
\hline 1 & 3 & 1 & - & 3 \\
\hline 2 & 2 & 1 & - & 5 \\
\hline 3 & 1 & - & - & 1 \\
\hline 4 & 2 & 1 & 1 & 4 \\
\hline
\end{tabular}


Table 3

Used ideas (low proficiency students)

\begin{tabular}{|c|c|c|c|c|}
\hline \multicolumn{5}{|c|}{ Low proficiency students } \\
\hline Text's ideas & In one sentence & In one paragraph & $\begin{array}{c}\text { Across } \\
\text { two paragraphs }\end{array}$ & Total \\
\hline 1 & 3 & - & 1 & 4 \\
\hline 2 & 2 & 1 & - & 5 \\
\hline 3 & 1 & - & - & 1 \\
\hline 4 & 2 & 1 & - & 3 \\
\hline
\end{tabular}

Furthermore, semantic relations within the sentence or across sentences, differ among students of different levels. High proficiency students have very good results in syntactic units compared to the low and average proficiency students. The high proficiency student achieves this by using anaphoric pronouns. For example:

The use of anaphoric pronouns

paragraph 1, line 2: These targets $\rightarrow$ which

paragraph 1, line 4: European Union $\rightarrow$ it

paragraph 4, line 4: In addition, the changes $\rightarrow$ They

paragraph 4, line 4: Emissions will occur again in the future $\rightarrow$ they will continue to occur

paragraph 7, line 2: the Russian Federation, Canada, and the Scandinavian and Baltic countries $\rightarrow$ they

paragraph 7, line 3: northern countries $\rightarrow$ Them

The low proficiency students use the anaphoric pronoun, but they fail to establish a connection between sentences. They simply use original text sentences without combining them into a coherent whole.

Skilled students achieve cohesion within and across sentences using prepositional phrases which establish relations between names and verbs, in order to achieve cohesion in the sentence, while the low proficiency students use linking tools that can be found in the original text.

In addition, the high proficiency students use prepositional phrases, or conjunctions more effectively than low proficiency students. The usage of several prepositional phrases helps students to achieve cohesion of complex ideas in the summary.

Moreover, in a text summary students join two or more sentences together; through coordination or subordination, but there is a difference in 
the amount of used linking words such as: but, and, which by many linguists are considered conjunctions.

What are conjunctions? According to the current definition; a conjunction is an unchangeable part of speech, which connects two parts of a sentence or two sentences and expresses syntactic relationships between them (Albanian Language Grammar, 1995).

It is only used when we want to do a simple morpho-syntactic analysis in terms of sentence or paragraph. However, we have not spoken about a summary of the sentence or paragraph, but we have discussed a summary of the text along with coherence, ideas and cohesion of this text.

Being discussed in terms of the text these linking tools are called literal conjunctions - these tools are used to assure the logical continuation of the text (K. Dibra \& N. Varfi Text Linguistics, Albatros, 2007).

One of the most important summary strategies during a text summarization is the production of the original text's main ideas. The production of ideas in the summary is done through the combination of these ideas within and across paragraphs.

Results show that students with different levels of proficiency are generally able to combine ideas within a paragraph, but find it difficult to combine the ideas which are in two or more paragraphs.

This result supports the previous studies (Sherrad 1986), which stated that even high proficiency students are able to combine ideas when they are in the same paragraph, but they face difficulties and do not have good results when ideas expand into all paragraphs.

In various literary texts, where most of the ideas are in separate paragraphs, students find it appropriate to reproduce them without having to combine those with ideas found in other paragraphs. This means that if two or three ideas are in the same paragraph, the student does not consider it reasonable to combine them with other ideas in different paragraphs.

The text summarization and the combining of ideas also depends on the organization of the text; as it is the cohesive phenomenon, acting, time and aspect, which reassures and provides a logical continuation of the discourse and the text coherence.

Combining ideas from different paragraphs depends on how ideas are connected not only with the semantic organization, but also with the thematic pragmatic text organization.

Another text summary strategy is linguistic and syntactic generalization. Generally speaking, students write long sentences instead of simple sentences and prefer to copy them without knowing how complex these sentences are. 
Results show that low proficiency students do not fully understand the original text and try to reproduce these confused ideas which do not complement each other and have no logical relationship between them, whereas high proficiency students have developed accurate ideas.

These results indicate that students do not use language generalization as a summarization strategy during text summaries. They produce indirect sentences, hoping that they would somehow convey the intended message. While high proficiency students' summaries are well coordinated; it can be said that low proficiency students have two problems; the understanding of the original text, as well as the required information production.

Syntactic generalization is the omission of main ideas as a result of a misinterpretation of the original text, or due to a bad production in the summarization process. Even here, we have different results among high proficiency and low proficiency students. It can be noted in the production of ideas, where skilled students produced four of five ideas of the original text, while unskilled students could produce up to two ideas, but there were also cases when they did not produce any ideas.

During the summarization process, there were also cases of distortion. These distortions are obvious in the omission of important ideas from the original text and the addition of those ideas that do not exist in that text. The omission of important information or ideas from the text shows the difference between low and proficiency students. Low proficiency students omit almost more than twice the ideas or information omitted by high proficiency students. This occurs because they do not apply the recognition process (Goodman, 1996).

However, distortion occurs not only when we remove information, but also when supplementary information is added. In this case we have distortion because additional information is not part of what is in the original text. The addition of ideas or information as well as the omission of these ideas or information reveals that students have problems with understanding the original text.

Another distortion that occurs in the text summarization process, is at the sentence level, changing the original text meaning. This is because of the wrong usage of nouns, and the subject-verb inconsistency. Summaries results show that high proficiency students do not distort or break the nounverb combination and their agreement rules.

Summaries made by low proficiency students contain many grammatical errors regarding subject-verb agreements. There is also inaccuracy in the use of pronouns, number and gender. The same errors occur with the use 
of verbs. These distortions not only distort the ideas of the text, but they also do not accomplish the students' purpose.

The table below shows distortions in idea unit level and sentence level:

Table 4

Distortions in different levels in the text

\begin{tabular}{|l|c|c|c|c|}
\hline \multicolumn{1}{|c|}{ No } & \multicolumn{2}{c|}{ Idea level } & \multicolumn{2}{c|}{ Sentence level } \\
\hline Students & $\begin{array}{c}\text { Deleted } \\
\text { Information }\end{array}$ & $\begin{array}{c}\text { Added } \\
\text { Information }\end{array}$ & Wrong subject & Wrong verb \\
\hline Good Students & 7 & 2 & 1 & - \\
\hline Average Students & 10 & 7 & 3 & 2 \\
\hline Weak Students & 2 & - & 8 & 12 \\
\hline
\end{tabular}

The results of these summaries show that low proficiency students do not reproduce the ideas of the original text, whereas high proficiency students do reproduce them. Another difference between the two levels is that high proficiency students coordinate ideas much better and do not distort them as low proficiency students do.

Also, students at different levels write long sentences and the low level students have many shortcomings in coherence.

\section{Conclusions and recommendations}

The summaries show that skilled students are more likely able to paraphrase the main ideas than unskilled students who prefer to reproduce ideas without transforming them.

Similarly, skilled students connect their ideas more cohesively, using semantic and anaphoric phrases more often than low proficiency students, who use the ideas as they appear in the original text.

The difference between high and low proficiency students is more visible when it comes to the use of ideas, in which some provisions are united in others to produce coherent syntactic structures. Summaries suggest that high proficiency students are much better than low proficiency students in the way they coordinate ideas.

However, there is no big difference between high and average proficiency students - in how they use linking words. The summaries show that high proficiency students are more efficient and tend to declare the main ideas in a general way. In addition, summaries show that high and average profi- 
ciency students, generally, do not simplify ideas and are much more able to identify these ideas.

Above all, students' summaries confirm that high proficiency students, unlike low proficiency students do not distort the ideas of the original text.

The summaries show that students of different levels are only able to combine the ideas that they can find in one paragraph, but they find it difficult to relate ideas that are in two or more paragraphs. The summaries show that students of different levels write long sentences but generally do not add personal opinions which do not appear in the original text.

There is a great need for further research on summary strategies. As we can recognize, the key term used in this paper is 'strategy'; therefore, the study of summary strategies used by students of the English Language Department at the University of Vlora is part of the search for a greater understanding of the conscious steps taken by second language students about information processing.

More research on the text summary should be conducted in the Albanian language, as there is no scientific research on summary strategies. Furthermore, even in other English-speaking countries this research was neglected by failing to develop a strong theory on summary strategies. Personally, I think these strategies are closely related to teaching and learning individual language skills.

From my teaching experience, I emphasize that there are materials on teaching and learning strategies, but there is a lack of materials on text information processing and summarizing strategies.

If we had the proper material on summarizing strategies, it could help us to know how students organize their cognitive skills in literary text summarizing. Knowing these skills would enable us to become better acquainted with the terms skilled and unskilled student. We also need to deepen the study by comparing how a skilled student processes the literary text compared to a unskilled student. In this way, we have also studied their learning process.

Despite different learning skills and strategies, no summary strategy has been taught in advance to students during their university lectures, other than the summary tasks they have performed in various subjects in high schools.

\section{N O T E S}

1 Clark, C. H. (1982). Assessing free recall, The Reading Teacher, 35, 434-439.

2 Revised enhanced lecture in opposition to the Kyoto Protocol on reducing greenhouse gas emissions 
Countries that sign the Kyoto Protocol accept mandatory targets on greenhouse gas emissions. These targets range from $-8 \%$ to +10 percent of each country's 1990 levels. This will result in a reduction of 5\% below 1990 levels in the period from 2008 to 2012 . The called-for reductions are $8 \%$ in the European Union and most of Europe. They are $7 \%$ in the United States and $6 \%$ in Canada. New Zealand, Russia, and Ukraine are to stabilize their emissions. Some countries, such as Norway, may increase emissions up to $1 \%$.

Countries can make up for not meeting their targets by increasing 'sinks'. These are forests that remove $\mathrm{CO}_{2}$ from the atmosphere. They can do this in their own countries, or they can pay for projects that have the same result in other countries.

The protocol will take effect when 55 countries have ratified it. Many of those must include the industrialized countries that account for most emissions. The United States and Australia have already indicated that they will not support the treaty.

There are many reasons why this protocol should not be accepted by the international community. Most scientists have concluded that recent increases in surface and atmospheric temperatures of the earth are part of a natural trend. These kinds of changes have occurred many times in the earth's history, and they will occur again in the future. In addition, the changes are very gradual, providing time for more research and consultation among nations.

There is no need to make drastic changes to decrease the emissions of greenhouse gases. There is no evidence that this will alleviate the situation. We should take a wait-and-see point of view before rushing into something that scientists don't support.

There is also the danger of severe economic decline. Prominent economists have predicted a $20 \%$ decline in economic activity, especially in the industrialized countries most impacted by the rotocol.

We should also consider that there are benefits to global warming. Growing seasons in northern climates, such as the Russian Federation, Canada, and the Scandinavian and Baltic countries would be lengthened, permitting them to increase agricultural production.

The protocol is not fair to western industrialized nations. They would be placed at a severe economic disadvantage to newly industrializing nations, such as China and India, which would be subject to the Kyoto Protocol. They would have to reduce emissions, while developing and least-developed countries could increase their emissions without penalty. The net result would be more greenhouse gas emissions than before the Kyoto Protocol.

We must stop listening the minority of scientists and far-out environmentalists who tell us that the sky is falling. Their research is not scientifically based, and we should instead listen to those who advocate a cautious approach. Some of those crazies even claim that sea levels will rise and that many islands nations and coastal areas will be inundated by the sea. This is nonsense. It has not happened yet, and it won't happen.

We must also protect ourselves against the bogus claims of rabid environmentalists, who would take us back to the Stone Age. Once we begin to limit greenhouse gas emissions, the world will begin a slide backwards in development that will cause millions of people to starve all over the world. As the world economy degrades, what we all know as a middle-class lifestyle will disappear, with everyone shivering in the cold and without employment.

\section{R E F E R E N C E S}

Adamson, H. D. (1992). Academic competence: Theory and classroom practice. New York: Longman.

Aebersold, J. A., \& Field, M. L. (1997). From reader to reading teacher. Cambridge: Cambridge University Press. 
Agalliu, F. \& Demiraj, S. (1995). Gramatika e gjuhës shqipe / 1 Morfologija. Tirana: Tiranë Akad. e Shkencave e Republikës së Shqipërisë, Inst. i Gjuhësisë Dhe i Letërsisë.

Baba, K. (2009). Aspects of lexical proficiency in Writing summaries in a foreign language. Journal of Second Language Writing, 18, 191-208.

Baumann, J. F., \& Johnson, D. D. (Eds.). (1984). Reading instruction and the beginning teacher: A practical guide. Minneapolis: Burgess Publishing.

Baumann, J. F. (1984). Standardized reading test scores and teachers. Minneapolis: Burgess Publishing.

Brophy, J., \& Good, T. (1986). Teacher behavior and student achievement. In Wittrock M.C. (Ed.), Handbook of research on teaching (3rd ed.). New York: McMillan.

Brown, A. S., Day, J. D., \& Jones R. S. (1983). The development of plans for summarizing texts. Child Development, 54(4), 968-979.

Campbell, J., Smith, D., \& Brooker, R. (1998). From conception to performance: How undergraduate students conceptualize and construct essays. Higher Education, 36, 449-469.

Carrell, P. L. (1992). Awareness of text structure: Effects on recall. Language Learning, 42(1), 1-18.

Chamot, A. U., \& O'Malley, J. M. (1996). Implementing the Cognitive Academic Language Learning Approach (CALLA). In R. Oxford (Ed.), Language Learning Strategies Around the World: Cross-cultural Perspectives. Manoa: University of Hawaii Press, 167-174.

Chandler, J. (2003). The Efficacy of Various Kinds of Error Feedback for Improvement in the Accuracy and Fluency of L2 Student Writing. Journal of Second Language Writing, 12, 267-296.

Chimbganda, A. B. (2003). Summarizing strategies used by low and high proficiency students ESL first year science students of the University of Botswana: A cognitive and meta-cognitive analysis. Botswana Journal of Applied Linguistics, $1,28-47$.

Cohen, A.D. (1998). Strategies in Learning and Using a Second Language. Essex, U.K.: Longman.

Corder-Ponce, Ë. L. (2000). Summarization interaction: Effects on foreign language comprehension and summarization of expository texts. Reading Research and Instruction, 39(4), 329-350.

Dibra, K. \& Varfi, N. (2007). Gjuhesi Tekst. Tirana: Albatros.

Ellis, R. (1987). Understanding second language acquisition. Oxford: Oxford University Press.

Ferris, D. \& Roberts, B. (2001). Error feedback in L2 writing classes. Journal of Second Language Writing, 10(3), 161-184.

Gee (1990, 1991, 2000, 2001) Social linguistics and literacies: Ideology in discourses. London: Falmer Press. 
Gee, J. P. (1992). The social mind: Language, ideology, and social practice. Series in language and ideology. New York: Bergin \& Garvey.

Gee, J. P. (1999). An introduction to Discourse analysis: theory and method. London and New York: Routledge.

Gee, J. P. (2000). Identity as an analytic lens for research in education. Review of Research in Education, 25, 99-125.

Goodman, K. S. (1996). On reading. Portsmouth, NH: Heinemann Smith.

Horiba, Y. (1996). Comprehension Processes in L2 reading: Language competence, textual coherence, and inferences. Studies in Second Language Acquisition, 18(4), 433-473, doi: 10.1017/S0272263100015370.

Johns, A. M., \& Mayes, P. (1990). An analysis of Summary Protocols of University ESL students. Applied Linguistics, Vol. 11, no. 3, 251-271.

McAnulty, (1981). Paraphrase, Summary, Precis: Advantages, Definitions, Models. Teaching English in the Two-Year College, vol. 8, no 1, 47-51.

Marzano, R. J., Pickering D. J., \& Pollock, J. E. (2001). Classroom Instruction that Works: Research-Based Strategies for Increasing Student Achievement. Alexandria (VA): Association for Supervision and Curriculum Development.

O’Malley, J. M. \& Chamot, A. U. (1990). Learning Strategies in Second Language Acquisition. Cambridge: Cambridge University Press.

Oxford, R. L. (1990). Language Learning Strategies: What Every Teacher Should Know. Boston: Heinle \& Heinle.

Oxford, R. L. (1999a). Language Learning Strategies in the Context of Autonomy, Synthesis of Findings from the International Invitational Conference on Learning Strategy Research, Teachers College, Columbia University, New York, NY.

Oxford, R. L. (1999b). Relationships between learning strategy use and language proficiency in the context of learner autonomy and self-regulation. In Bobb L. (Ed.), Learner Autonomy as a Central Concept of Foreign Language Learning, Special Issue of Revista Canaria de Estudios Ingleses, 38, 109-126.

Sherrard, C. (1986). Summary Writing: A Topographical Study. System, 17(1), $1-11$.

Smith, F. (1994). Understanding reading: A psycholinguistic analysis of reading and learning to read. (5th ed.). Hillsdale, NJ: Erlbaum.

Street, B. (1984). Literacy in Theory and Practice. Cambridge: Cambridge University Press.

Street, B. (1988). Literacy practices and literacy myths. In Saljo R. (Ed.), The Written Word: Studies in Literate Thought and Action. Springer-Verlag Press, 59-72.

Street, B. (1995) Social Literacies. Longman: London.

Street, B. (2005) (Ed.) Literacies Across Educational Contexts. Philadelphia: Caslon Publishing. 
Street, B. (2000). Literacy Events and Literacy Practices. In Martin-Jones, M. \& Jones, K. (Ed.), Multilingual Literacies: Comparative Perspectives on Research and Practice. Amsterdam: John Benjamins, 17-29.

Street, B. (2001) (Ed.) Literacy and Development: ethnographic perspectives. London: Routledge.

Taillefer, G. (1996). L2 reading ability: Further insights into the short-circuit hypothesis. Modern Language Journal, 80, 461-477.

Winograd, P. N. (1984). Strategic difficulties in summarizing texts. Reading Research Quarterly, 19(4), 404-425.

Zwann, R. A., \& Brown, C. M. (1996). The influence of language proficiency and comprehension skills on situation model construction. Discourse Processes, $21(3), 289-327$. 